Running Head: FIRESETTING OFFENSE CHAIN MODEL (FOC-MD)

\title{
A Firesetting Offense Chain for Mentally Disordered Offenders (FOC-MD)
}

\author{
Nichola Tyler ${ }^{\text {ab }}$, Theresa A. Gannon ${ }^{\text {ab }}$, Lona Lockerbie ${ }^{\text {ba }}$, Tracy King ${ }^{\mathrm{c}}$, Geoffrey L. Dickens ${ }^{\mathrm{d}}$ \\ $\&$ Calem De Burca ${ }^{\mathrm{e}}$ \\ ${ }^{\text {a } U n i v e r s i t y ~ o f ~ K e n t, ~ U K ~}$ \\ ${ }^{b}$ Kent Forensic Psychiatry Services, UK \\ ${ }^{\mathbf{c}}$ Aegypt Clinic, Sevenoaks, UK \\ d St. Andrews Academic Centre, King’s College London Institute of Psychiatry, \\ Northampton, UK \\ ${ }^{\mathrm{e}}$ University of Oxford, UK
}

Please cite as: Tyler, N., Gannon, T. A., Lockerbie, L., King, T., Dickens, G. L., \& De Burca, C. (2014). A firesetting offence chain for mentally disordered offenders (FOC-MD). Criminal Justice and Behavior, 41, 512-530. doi: 10.1177/0093854813510911

Available from: http://cjb.sagepub.com/content/41/4/512. 


\begin{abstract}
Relatively little effort has been made to develop and validate theories that explain firesetting. In this study the first offense chain model of firesetting in mentally disordered offenders was developed. Twenty-three mentally disordered firesetters were interviewed about the affective, cognitive, behavioral and contextual factors leading up to and surrounding one of their recorded firesetting offenses. Offense account interviews were analysed using groundedtheory. The resulting model consists of four main phases: (1) background, (2) early adulthood, (3) pre-offense period, and (4) offense, and post offense period. The model accounts for firesetting by both male and female mentally disordered offenders and highlights the importance of early childhood experiences of fire and the onset of mental illness as precursors to firesetting within this population. Further, the model is able to distinguish between different types of mentally disordered firesetters and their offense styles. The clinical implications and utility of the model are also discussed.
\end{abstract}

Key words: Arson, Firesetting, Mentally Disordered Offenders, Grounded Theory, Offense Chain Model. 


\section{Firesetting in Mentally Disordered Offenders}

In England and Wales in 2009/2010 there were 32,579 cases of arson recorded by the police (Home Office, 2012) and in 2009 3\% of offenders brought before the courts on arson charges received hospital orders and limitation directions (combined hospital order and custodial sentence; Ministry of Justice, 2011). 'Arson' is a legal term describing unlawful damage or destruction of property either recklessly or intentionally by using fire (Criminal Damage Act, 1971). The definition of arson varies across jurisdictions and does not incorporate those deliberately set fires that have not resulted in a formal conviction for arson (Gannon \& Pina, 2010). The term 'firesetting', however, is an overarching term that can account for the many different types of deliberately set fires that may or may not have resulted in an arson conviction (Dickens \& Sugarman, 2012).

The presence of a mental disorder is frequently reported as a risk factor for firesetting in the literature (Barnett, Richter, Sigmund, \& Spitzer, 1997; Dickens et al., 2009). It has also been suggested that firesetting is especially prevalent amongst the mentally disordered offender population, (Swaffer, Haggett, \& Oxley, 2001), with prevalence rates estimated as being approximately 10\% (Coid, Kahtan, Gault, Cook, \& Jarman, 2001; Fazel \& Grann, 2002; Repo, Virkkunen, Rawlings, \& Linnoila, 1997). This rate appears to be consistent with those found in community samples (11\%; Gannon \& Barrowcliffe, 2012), however, it is not known as yet how these prevalence rates compare to that of a non-mentally disordered offender population. Despite the suggested prevalence of firesetting in forensic psychiatric services there are very few specific treatment programs available for mentally disordered firesetters (Palmer, Caulfield, \& Hollin, 2007; for exceptions see Swaffer, Haggett, \& Oxley, 2001; Gannon, Lockerbie, \& Tyler, 2012; Taylor, Thorne, Robertson, \& Avery, 2002). This is presumably due to poor understanding of the link between mental disorder and firesetting 
(Hollin, 2012; Tyler \& Gannon, 2012) and lack of research and theory regarding the dynamic risk factors associated with firesetting (Palmer, Hollin, Hatcher, \& Ayres, 2010).

\section{Theories of Firesetting}

To date, there has been a lack of focus in the firesetting literature on developing theories that fully explain acts of firesetting in comparison to other areas of offending such as sexual and violent offending. Further, no specific theories have been developed to explain firesetting in mentally disordered offenders. Several theories attempt to explain firesetting behavior via the elucidation of a single factor (i.e., single factor theories; Ward \& Hudson, 1998). However, since these theories focus on one particular area of psychological functioning (e.g., sexual interest, Freud, 1932; social learning, Gannon \& Pina, 2010, Vreeland \& Levin, 1980; biological disorder, see Barnett \& Spitzer, 1994) they are limited in their scope and are unable to account for (1) the complex interaction of multiple psychological factors that may precipitate firesetting, and (2) the full range of motives that have been identified in the literature for firesetting by mentally disordered offenders.

There are currently only three multifactor theories that exist to explain adult firesetting. The most widely cited multifactor theories are Functional Analysis Theory (Jackson, Hope, \& Glass, 1987; Jackson, 1994) and Dynamic Behavior Theory (Fineman, 1980; 1995). Both Jackson et al.'s and Fineman's theories give a comprehensive account of the antecedents to adult firesetting with particular emphasis placed on developmental factors. However, a criticism of both of these theories are that they are unable to account for all the potential dynamic risk factors that may be associated with the variety of firesetting behaviors encountered by clinicians in treatment (see Gannon \& Pina, 2010). One relatively new multifactor theory that holds particular promise is The Multi-Trajectory Theory of Adult Firesetting (M-TTAF; Gannon, Ó Ciardha, Doley, \& Alleyne, 2012). The M-TTAF was developed by Gannon and colleagues using a theory-knitting approach (Kalmar \& Sternberg, 
1988); incorporating elements of the multifactor and single factor theories described above as well as contemporary empirical evidence to construct a comprehensive account of adult firesetting for both male and female, mentally disordered and non-mentally disordered offenders. Further, the M-TTAF is a two tiered theory that not only outlines the antecedents of deliberate firesetting in adults but also identifies the different subtypes of firesetter and their associated treatment needs. Whilst the M-TTAF provides a comprehensive theoretical basis on which to develop treatment programs for firesetting, however, it is also limited in its scope as it lacks detail regarding how the offense process actually unfolds for mentally disordered firesetters.

Given the lack of single and multifactor theories in the area of firesetting it is not surprising that there are no existing micro-theories to explain this behavior. Micro-theories tell us what offenders do or key factors that occur in the moment immediately before, during, and after the offense (Ward, Polaschek, \& Beech, 2006). They are dynamic in nature and provide in-depth accounts of the offense process and associated factors (i.e. cognitive, affective, behavioral, situational and contextual) over time, making them useful for outlining the sequence of events preceding and surrounding an offense (Ward et al., 2006). Microtheories are data driven and are developed from either objective (e.g., interviews with offenders) or subjective data (e.g., police and prison reports) using qualitative research methods (i.e., grounded theory, Strauss \& Corbin, 1998).

One type of micro-theory that has proved to be particularly informative and valuable for the assessment and treatment of different types of offenders is the offense chain model (e.g., Cassar, Thakker, \& Ward, 2003; Gannon, Rose, \& Ward, 2008; Murdoch, Vess, \& Ward, 2011; Ward, Louden, Hudson, \& Marshall, 1995). Offense chain models have shed light on the offense processes of different types of offenders and highlighted focus points for treatment which had previously been overlooked. For example, Ward et al. (1995), who were 
the first to adopt this approach with male child sexual offenders, found that contrary to popular belief there was more than the one traditional pathway to child sexual offending (i.e., both an approach pathway-characterized by negative affect and under-controlled selfregulation-and an avoidant pathway-characterized by positive affect and intact selfregulation), highlighting the diverse nature of this population. Similarly, Cassar et al. (2003) developed an offense chain model for homicide offenders. This demonstrated the importance of cognitive processes and affective states and their effects on the reasons for committing the crime; something which had been omitted from previous research. Further, Gannon et al.'s (2008) descriptive model of the offense process for female sexual offenders emphasised several salient differences in both the background and pre-offense period of female sexual offenders compared with male sexual offenders (e.g., more severe abusive developmental experiences and experiences of domestic abuse proximal to offending in comparison to male sexual offenders). Taken as a whole, offense chain models have proven highly valuable for professionals working in the assessment and treatment of offenders as they have highlighted key dynamic risk factors to focus on as part of treatment and provided the basis for further areas of research and theory development for different subtypes of offenders (Chambers, Ward, Eccleston, \& Brown, 2009).

The primary aim of this study was to develop the first offense chain model of the offense process for mentally disordered firesetters. Given the dearth of theory and research into adult firesetting in comparison with other types of offending and the absence of empirically evidenced treatment models, developing a descriptive account of the offense chain of mentally disordered offenders was considered paramount for developing the knowledge and theory base in this area. Grounded theory was considered particularly appropriate as a method since the core focus of this approach is to develop theories or models in areas where there is little guiding research or theory (Ward et al., 2006). 


\section{Method}

\section{Participants}

Twenty-three mentally disordered offenders (16 males and 7 females) were recruited from two medium secure psychiatric hospitals $(n=18)$ and four prison establishments $(n=5)$ in England. All participants had a diagnosed mental illness in the run up to and at the time of setting the fire(s) and had at least one recorded incident of firesetting in their offense history, nine held an index offense of arson (total number of firesetting incidents range from $1-8$ ). Sixteen participants had multiple incidents of firesetting in their records. Approximately half of participants had set between 1 and 3 fires prior to the one they discussed for the purpose of this study $(n=12)$, the rest had either set more than 3 previous fires $(n=5)$ or none $(n=6)$. All participants had at least one current diagnosed mental disorder. Psychiatric diagnoses included schizophrenic disorders (i.e. schizophrenia and schizo-affective disorder; $n=15$ ), personality disorders (including Borderline Personality Disorder and Antisocial Personality Disorder, $(n=7)$, bipolar affective disorder $(n=2)$, substance misuse $(n=2)$, drug induced psychosis $(n=3)$, borderline intellectual disability $(n=2)$, hyper-mania $(n=1)$, mental and behavioral disorder $(n=1)$, and obsessive compulsive disorder $(n=1)$. The majority of participants had more than one diagnosed mental disorder $(65.2 \% n=15)$. Participant's ages ranged from 24 to $64(M=39.13 ; S D=11.52)$ and the majority were White British/Irish $(83.3 \%, n=20)$. The majority of participants had set the fires discussed for the purpose of this study on their own $(86.9 \%, n=20)$.

\section{Procedure}

Data was collected by the first, second, fourth and sixth authors. A semi-structured interview schedule was constructed by the first and second authors, adapted from interview schedules used in previous offense process research (i.e., Gannon et al., 2008). During the interview, participants were asked to describe the events, thoughts, and feelings leading up to, 
and surrounding one of their recorded firesetting offenses ${ }^{1}$. Seventeen of the twenty-three participants completed an interview whilst the remaining six participants declined to be interviewed but consented to accounts of their firesetting offense to be copied from reports in their hospital/prison records. The majority of interviews were recorded on a digital audio recorder with the participant's knowledge and informed consent. However, two participants did not wish to be recorded so their accounts were recorded in note form by the interviewer. All interviews were transcribed verbatim and were on average 47.36 minutes in length (range 14.07-69.00 minutes).

\section{Data Analysis}

Interviews were transcribed and the data analysed by the first author using grounded theory analysis (Strauss \& Corbin, 1998). The main aim of grounded theory is to develop theories or models from participants' own experiences in areas where there is little guiding research or theory. There are three main stages to grounded theory analysis. The first stage of analysis is termed open coding (Strauss \& Corbin, 1998) and involves breaking the data down, line by line, into small units of basic meaning that stand alone in the context of the research question (i.e., 'what factors precipitate firesetting in mentally disordered offenders?'), commonly termed meaning units (Strauss \& Corbin, 1998). These basic meaning units are then abstracted into more general meaning units by allocating descriptive labels that represent the characteristics/properties of the meaning units. General meaning units are then assigned to one or more low-level categories based on their conceptual similarity with other meaning units (e.g., based on occurrences or phenomena; Willig, 2008). Since grounded theory is a cyclical process (Gordon-Finlayson, 2010) constant comparison between general meaning units and low-level categories are made throughout analysis and

\footnotetext{
${ }^{1}$ In line with previous offence chain research (e.g., Murdoch et al., 2010, 2011) participants were asked to choose one fire that they could clearly recall for the purpose of the interview.
} 
categories are refined and added accordingly. After the initial low-level categories have been derived these are then linked with other low-level categories based on their shared conceptual similarity, creating major over-arching categories, commonly termed axial coding (Strauss \& Corbin, 1998). Subcategories are also developed to give the overarching categories contextual meaning where relevant. This stage is analytical and involves the interpretation of events to gain an understanding of the phenomena being studied (Strauss \& Corbin, 1998).

Following this analytical process, the major over-arching categories, along with their subcategories, were integrated chronologically to form a preliminary model for approximately two thirds of the participants $(n=14)$ to describe the sequence of events pre, during and post firesetting. The remaining nine transcripts were then plotted through the preliminary model to test its validity. During this process the researcher was constantly comparing the transcript's fit with the existing categories of the preliminary model (constant comparison) and refinements and addition of new categories were made where appropriate. For example, "motive" subcategories such as crime concealment and suicide/self harm were added and refinements were made to some of the subcategories (e.g., to "watch fire"). Similarly to other offense chain research, data collection and analysis continued in this cyclical manner until theoretical saturation had been reached (Gannon et al., 2008). It is also important to note that to reduce researcher bias model development was completed by both the first and second authors together. Since the aim of grounded theory is to produce a descriptive account of a particular phenomenon and not an overarching generalizable theory, the final preliminary model outlines the sequence of events (emotional, cognitive, and behavioral) that precede and surround a single incidence of firesetting for the mentally disordered offenders in our sample.

\section{Reliability and Validity}


In order to assure data validity participants' hospital and prison files were examined post interview to ensure that the offense narratives provided by participants were accurate in content. Any information provided by participants in the interviews that significantly differed from file information was removed from analysis to strengthen and maintain the model validity. In addition to this, the second author and a rater independent to the research made spot checks throughout the open coding (e.g., to check for over/under-coding of meaning units) and axial coding phases of analysis (e.g., to ensure that linked low-level categories shared similar conceptual meaning, and to ensure category titles accurately reflected the linked concepts.)

\section{Results}

The final preliminary model that has been developed outlines the sequence of thoughts, feelings, behaviors, and events that precede and surround a single incidence of firesetting in mentally disordered offenders. This model can be divided into four main phases: (1) Background Factors; which accounts for historical factors in the offender's childhood and adolescence (see Figure 1), (2) Early Adulthood (see Figure 2), (3) Pre-Offense Period; factors that occur in the offender's early adulthood and in the period up until immediately prior to the fire (see Figure 2), and (4) Offense and Post Offense Period; factors that occur during and immediately after the fire (see Figure 3).

\section{Phase 1: Background Factors}

The first category to emerge within the model was caregiver experiences. Caregiver experiences describe participant's relationships with their parents/step-parents during childhood and/or adolescence. Caregiver experiences were either predominately negative (e.g., poor relationships with one or both parents or step-parents, parental absence throughout childhood) or positive (e.g., stable household, good relationship with parents, both parents 
present during upbringing). The majority of participants experienced negative caregiver relationships in childhood and/or adolescence $(n=14)$ with a significant proportion of these describing poor relationships with their mother $(n=6)$. However, if a parent was reported to have been consistently absent in childhood (i.e., had no involvement in the participant's upbringing) it was typically the father. A family history of mental health issues or substance abuse was present amongst ten of the fourteen participants who had negative caregiver experiences. These factors tended to impact upon participants' relationships with their caregivers in a negative manner (i.e., substance abuse increased the likelihood caregivers exhibiting verbal and physical aggression).

The next major category to emerge from our analysis was separation experiences. This category describes whether participants were removed from their primary caregivers or not during childhood and adolescence. Separation experiences generally occurred as a result of negative caregiver experiences. Three subcategories were noted within this overarching category: care, extended family, and none. Participants who were removed from their caregivers were mostly taken into care $(n=6)$ or taken to live with extended family $(n=2)$. Those participants who went to live with extended family were either removed from their parents' home by social services and relocated to extended family or removed by extended family members themselves. In addition, some participants were periodically separated from their parents on more than one occasion during childhood and early adolescence but returned to live with their parents (depicted by the double headed arrows returning to caregiver experiences from care and extended family in Figure 1). However, approximately two thirds of participants $(n=15)$ did not have any separation experiences from caregivers during childhood and adolescence depicted by none in the model.

The third major category to emerge within Phase 1 of the model was abusive experiences. Abusive experiences describes whether participants were victims of abuse during 
childhood and/or adolescence. Four subcategories were noted within abusive experiences which were not mutually exclusive (i.e., some participants experienced more than one type of abuse): physical $(n=8)$, sexual $(n=7)$, emotional $(n=4)$ and none $(n=10)$. A large proportion of participants experienced some sort of abuse in childhood $(56.6 \%, n=13)$, with approximately $61 \%$ of these participants experiencing just one type of abuse. However, several participants experienced more than one type of abuse. The majority of those who experienced abuse were abused by individuals who were responsible for their care (e.g., parent or care staff), however, four participants were sexually abused by a stranger. Just under half of participants had not experienced any abuse in childhood and/or adolescence.

As a result of these early experiences, by the age of 18 , participants had all developed one or more risk factors that appeared to make them susceptible to setting fires. These risk factors were not mutually exclusive so all but three participants reported the development of multiple risk factors. These risk factors include fire related factors (i.e., early firesetting, strong affect towards fire, and fire interest), antisocial activity (e.g., early criminal behavior, acting antisocially), mental health problems (e.g., depression, schizophrenia, obsessive compulsive disorder), and maladaptive coping (e.g., substance misuse, social isolation, interpersonal aggression, self-harm). In terms of these fire related risk factors, early firesetting was engaged in by just over half of participants $(56.5 \%, n=13)$ for a myriad of reasons including boredom $(n=2)$, as a coping mechanism $(n=4)$, for gaining attention $(n=$ 1), problem solving $(n=2)$, excitement $(n=2)$ and revenge/anger $(n=2)$. Interestingly, following participants' early experiences of fire (be those general experiences or those related to their own firesetting), a strong affect towards fire tended to develop which was either predominantly positive or negative. Strong negative affect was characterized by an intense fear or strong aversion towards fire (e.g., "I used to have dreams about people catching on fire ... really horrible nightmares and that like ... I used to wake up like really scared like you 
know"). Interestingly, several participants who developed a strong negative affect towards fire also engaged in early firesetting and developed fire interest in childhood $(n=7)$. This might suggest that individuals who develop strong negative affect towards fire may also develop an implicit association between fire and a tool that can be used in a harmful way (e.g., for revenge), as a result of their own negative experiences with fire. In contrast to this, strong positive affect towards fire, was generally characterized by feelings of excitement and pleasure (e.g., "I used to get a matchbox and then light it, like watch the whole lot light up and the whole thing burn, everything burn, I ended up getting excited"). This participant's early experiences with fire elicited strong positive affect towards fire (i.e., excitement) which further reinforced firesetting as a positive behavior for this individual. Fire interest, as the label suggests, describes participants who developed a fascination or interest in fire throughout childhood. Early firesetting, fire interest and a strong affect towards fire (either positive or negative) appeared to develop concurrently. Approximately half of all participants exhibited all three fire risk factors.

Just over half of all participants $(56.5 \%, n=13)$ reported engaging in some sort of antisocial activity during childhood and/or adolescence. Types of antisocial activity included early offending and poor school behavior. This suggests that firesetting for some mentally disordered firesetters may be part of a spectrum of general antisocial behavior. In addition to this, just over two thirds of participants had developed some form of maladaptive coping by late adolescence $(72.2 \%, n=17)$. These coping strategies appeared to develop as a result of abusive experiences or negative caregiver experiences. The most prevalent type of maladaptive coping was substance abuse $(n=14)$ with a proportion of participants who developed this coping strategy also having developed a second type of maladaptive coping (e.g., interpersonal aggression, self-harm or social isolation; $n=6$ ). For example, some participants reported being violent towards peers as a way of coping with the physical abuse 
they experienced at home as well as taking drugs and/or alcohol to cope with negative affect experienced in relation to this. Interestingly, four participants' early firesetting appeared to be utilised as a coping strategy as a way of either drawing attention to a current problematic situation or coping with difficult emotions. Some participants also developed mental health problems (e.g., depression, paranoia) during childhood and adolescence $(n=9)$. These mental health problems exacerbated other risk factors that participants had developed, appearing to make them more chronic. For example, for some participants who had developed maladaptive coping skills (e.g., substance abuse, interpersonal aggression) due to their poor childhood experiences these were exacerbated by mental health problems (e.g., substance abuse increased further to cope with mental health issues).

\section{Phase 2: Early Adulthood}

Phase 2 of the model refers to mentally disordered firesetter's early adulthood experiences and the factors that occur during this period (Figure 2). Following childhood, mentally disordered firesetters enter Phase 2 of the model with numerous factors that put them at risk of setting a fire. These risk factors and fire related factors feed into problematic intimacy affecting participant's ability to develop and maintain healthy intimate relationships. All participants flowed through this category in the model having described various dysfunctional relationship experiences including abusive relationships, involvement in inappropriate and chaotic relationships as well as difficulties in forming intimate relationships, and high levels of promiscuous behavior. For participants who had pre-existing vulnerabilities such as mental health problems $(n=6)$ and/or substance misuse $(n=14)$ these either became more acute as a result of their relationship difficulties or were a direct cause of their relationship problems. The remaining participants $(n=7)$ still developed/entered problematic relationships during early adulthood and they attributed the subsequent deterioration in their mental health to have developed from problematic intimacy experiences. 


\section{Phase 3: Pre-Offense Period}

Phase 3 of the model refers to the period spanning from approximately 1 year prior up until moments before the offense and describes factors that occur during this period. During the pre-offense period all participants experienced mental health deterioration. This was either as a result of their relationship problems, substance misuse, or triggered by the experience of another life stressor/trauma which impacted upon participants' psychological wellbeing (e.g., miscarriage, child taken into care, being sent to prison/unexpectedly transferred prison). Consequently participants were either admitted to a psychiatric hospital $(n=6)$, engaged with mental health services in the community $(n=7)$, or did not have any contact with mental health services despite the deterioration of their mental health $(n=10)-$ this is reflected by the solid line from mental health deterioration down to poor problem solving (see Figure 2).

All participants appeared to exhibit poor problem solving skills in the period before the fire. Poor problem solving was often associated with a problem such as being discharged from hospital and not knowing how to cope, committing a non fire related crime and needing to conceal it, not knowing how to recognise and deal with fire interest, and not knowing how to cope with negative interpersonal relationships. Interestingly, for all participants, setting the fire appeared to be the ultimate selected problem solving strategy to resolve the issue they had, which feeds into the third stage of the model, the development of motive(s) to set a fire.

At some point in the pre-offense period participants developed motives(s) to offend. Ten motives for firesetting were evident in the data which were not mutually exclusive participants could hold one or more motives simultaneously. These motives to set the fire developed or began to develop anywhere from one year before the offense up until moments before setting the fire. Motive(s) reported by participants included boredom $(n=2)$, fire 
interest $(n=4)$, protection $(n=2)$, protest $(n=2)$, crime concealment $(n=1)$, hallucinations $(n=8)$, revenge/anger $(n=16)$, cry for help $(n=7)$, and suicide/self harm $(n=1)$.

Boredom, as the label suggests, refers to mentally disordered firesetters who were motivated by a need to relieve experiences of monotony. Both participants who expressed boredom as a motivator also reported being motivated by fire interest. Fire interest was reported as a motive for firesetting by four participants. Participants who had a motive of fire interest expressed an interest or excitement in anticipation of seeing the fire. All participants where a motivator of fire interest was evident in the data had developed risk factors of fire interest, early childhood firesetting, and a strong positive affect towards fire in childhood/adolescence.

Of particular note, two participants expressed being motivated by protection in their offense chain narratives. Participants who held the motive protection generally set the fire as a way of protecting themselves from perceived imminent violence/harm; this perception could either be delusional or a real perceived threat. For example, one male participant when asked about why he had set the fire stated “... I thought, maybe you're right, maybe if they see a fire these people will leave me alone and run away or do something". The fourth motive to be identified was protest. Protest describes participants who were motivated by a desire or need to express an objection against authority with regard to their current situation that they were put in. For example, both participants who expressed protest as a motivator set fire to their cells in prison as they did not want to be locked up (e.g. "I told him that if he doesn't get me out the cell I'm gonna burn the cell."). The next motive to be identified was crime concealment. Crime concealment $(n=1)$ refers to participants who reported being motivated to set a fire simply as a way to destroy evidence after having committed another offense.

Another motive reported by participants was hallucinations. Hallucinations generally developed as part of participants' mental health deterioration and were either a sole 
motivator for their firesetting (e.g., setting the fire purely under the instruction of hallucinations where no other motive was reported, $n=1$ ) or exacerbated other pre-existing motives (e.g., cry for help, revenge, $n=7$ ); these generally appeared to take the form of auditory command type hallucinations. For example, one participant when asked about their reasons for setting the fire said: "[The fire was] a cry for help ... [and] on the Sunday voices were telling me 'go on set it on fire. Show them, you'll get out of this flat now. Show them set it on fire"'. This suggests that hallucination may act in two ways, either as a direct motive for firesetting or by fuelling other existing motives.

As the label suggests, revenge/anger refers to mentally disordered firesetters who were motivated to offend in order to administer retribution in response to a perceived wrong or set the fire out of anger; this wrong could either have been directed towards themselves or towards another. For example, one participant when asked why he had set fire to his exgirlfriend's partners house stated, 'Yeah err she was sort of trapped erm ... and I was angry with this man and I guess in a way it was sort of like revenge and anger and everything all put into one, everything.' A female participant, when asked why she had set the fire to another patient's bed stated, "I suppose I set the fire because ... I set the fire thinking you know you're not going to mess with me girl. Fire hurts, fire burns, fire can kill." This highlights that there are two dimensions to firesetting motivated by revenge - seeking revenge for another or for oneself.

The next motive to emerge from the data was cry for help. Cry for help describes participants who were motivated to communicate a desire, wish, or need for help. Participants who possessed the motive of cry for help tended to express feelings of hopelessness, wanting to be rescued, wanting help, or wanting to be hospitalised that were associated with their motive for firesetting. These participants appear to use fire as a communication tool to help escape a difficult situation. The final motive identified in the data set was suicide/self harm. 
Participants who held this motive set the fire to either directly harm themselves or in an attempt to end their own life.

The target of the offense often became fully formulated shortly after any motive(s) had developed. Two subcategories of offense target were found among mentally disordered firesetters in the data: self-directed $(n=2)$ and other directed $(n=21)$. The sub-category of other directed could then be further divided into material or living. Self directed refers to those participants who the offense target was themselves. These mentally disordered firesetters either set fire to themselves or their own property either as a method of self harm or suicide. Externally directed describes participants for whom the offense target was either another person (living; $n=6$ ) or property (material; $n=15$ ). For those participants for whom the target of their firesetting was material, approximately half had set fire to their own property $(n=7)$ and the other half had set fire to someone else's property ( $n=8$; e.g., public property, prison property, someone else's house).

The next major category to emerge from the data was planning. Planning of the offense generally followed deciding on the target. Planning was generally quite proximal for all participants and tended to occur within a few days to a few minutes before the offense. Four main types of planning were apparent in the data: detailed explicit, low level explicit, implicit and none. Detailed explicit planning $(n=5)$ describes mentally disordered firesetters who acknowledge explicitly planning to set the fire. These participants generally planned setting the fire several hours or several days before the offense (e.g. packed their bags, removed batteries from smoke detectors, collected materials for the fire). Further, mentally disordered firesetters who had engaged in detailed explicit planning of the offense in detail were more likely to have at least two of the fire related risk factors during childhood/adolescence $(n=4)$. Low level explicit planning $(n=7)$ refers to participants who acknowledged some explicit planning of the offense but this planning occurred more 
proximally to setting the fire, an hour to minutes before. For example, deciding to use accelerants or ignition sources that were available on arrival at the scene. Participants who engaged in low level explicit planning all bar one had developed at least two of the fire risk factors in childhood and were generally motivated by revenge/anger $(n=5)$. Implicit planning $(n=3)$ describes those mentally disordered firesetters who did not appear to engage in any explicit planning regarding setting the fire, however, they acknowledge having thought about setting the fire in the days leading up to the offense. None $(n=8)$ describes participants who did not report any planning of the offense. Firesetting for these participants was generally impulsive or opportunistic (i.e., the fire was set because there was an available opportunity rather than a pre-planned target and/or method of firesetting).

Cognition and affect and substances (e.g., drugs and alcohol) both emerged as having a direct influence on planning (e.g., participants who were intoxicated were more likely to set the fire on impulse) in the data and cognition and affect could either be positive (e.g., "I just felt excited that I was going to see the fire. I just found it quite fascinating.") or negative in relation setting the fire (e.g., "I was thinking to myself 'this is you know this is going to go wrong unless I plan something out'.”). Participants who felt positively about the fire were more likely to engage in detailed planning of the offense.

\section{Phase 4: Offense and Post Offense Factors}

Phase 4 of the model describes the offense itself and the factors that occurred immediately post offense. During phase 4 of the model the fire itself is lit; the fire ignition aspect of the model refers specifically to how mentally disordered firesetters went about starting the fire. Two key subcategories within fire ignition were evident: use of fire knowledge and no use of fire knowledge. Approximately half of participants employed their use of fire knowledge when starting the fire $(n=12)$. This included the use of accelerants $(n=$ $6)$, use of specific flammable materials $(n=3)$, and the application of specific knowledge or 
previous fire experience regarding building/igniting the fire $(n=3)$. For example, one participant when asked how he set the fire stated, "I had a little round table in the room. I put the fire under it as I had worked out from Hospital L that if I set a fire under a shelf then it would catch fire". Interestingly, the majority of participants who had used fire knowledge when starting the fire had engaged in early firesetting, had strong fire affect, and had developed a fire interest in childhood $(66.6 \%, n=8)$. They also were likely to have explicitly planned the fire. Participants who did not use fire knowledge when starting the fire $(n=11)$ had generally either set the fire out of impulse or opportunity (no planning) or had engaged in low level planning of the offense and were less likely to have developed fire related risk factors in childhood.

The second category in Phase 4 of the model refers to the period during the offense itself. Fire related affect/cognition-fire describes the affect and cognition about the fire that mentally disordered firesetters reported to have experienced whilst initially igniting it and immediately after. Four main subcategories were evident for this main category: positive affect/cognition, mixed affect/cognition, negative affect/cognition and indifference. Positive affect/cognition reported to have been experienced by firesetters $(n=5)$ included excitement, relief, happiness, (e.g., "when I saw those flames, I just felt like everything I was feeling was coming out and I started to feel good, I started to feel happy.”) and positive thoughts about seeing the fire (e.g., "[It felt] like I've achieved something.”). For those participants who experienced mixed affect/cognition $(n=4)$ positive and negative affect/cognition appeared to be competing with one another. For example, participants were often excited or had positive cognitions about setting the fire or achieving their offense goal (e.g., revenge) but also experienced negative cognition/affect simultaneously (e.g., fear of detection/consequences, panic, negative evaluations of the situation). For example, one female patient stated, "I was just that enraged, all I wanted to do was hurt him ... I'm still gloating about it ... when it 
really took hold and he came down ... all I wanted to do was get out ... I actually opened the door and ran, 'cause I got too scared.”. Five participants reported experiencing negative affect/cognition during the fire. Negative affect/cognition that was evident in the data included fear, upset, (e.g., “....as it started going up I felt very scared ... I thought I was going to die.") and negative thoughts about the fire (e.g., "[I] Stood back and it was blowing all smoke and bits of paper were blowing about and thought 'oh no I've done a wrongun here, I shouldn't have done this'.”). Indifference refers to participants who reported not experiencing any strong internal arousal (affective or cognitive) towards the fire (i.e., were not excited or scared by the fire - any overwhelming affect/cognition experienced generally related to the situation rather than the fire itself); a significant proportion of participants in the data set reported feeling indifferent about the fire itself $(39 \%, n=9)$.

The final category in the model refers to whether participants watched the fire or not. This was divided into three subcategories: watched interested, did not watch-circumstances did not allow and did not watch - no interest. Just over half of participants watched the fire after having set it as they were interested $(n=9)$. Those participants who watched the fire had at least two of the fire related risk factors of (i.e., fire interest, a strong fire affect, early firesetting). Five participants reported not having watched the fire after setting it due to no interest; all but one of the participants in this category had not developed any of the fire risk factors in childhood. Finally, seven participants reported that they did not watch the fire as circumstances did not allow it. These participants generally set fire for revenge, protection or suicide and contextual circumstances (i.e., avoiding detection, protecting one-self) meant that they either did not stay and watch the fire after they had lit it or that the motive for setting the fire required them to be present for reasons other than interest (i.e., suicide attempt).

Whether participants watched the fire or not appeared to be related to the fire related cognition and affect participants experienced whilst also lighting the fire, indicated by the 
double headed arrows between fire related affect/cognition and watch fire. For example, the majority of participants who watched the fire generally experienced some form of positive affect/cognition (although sometimes mixed with competing negative affect) whilst igniting and watching the fire. Conversely, participants who did not watch the fire, either because they were not interested or because circumstances did not allow, were more likely to report feeling indifferent/negative about the fire once it had been lit.

A preliminary examination of the different routes or 'pathways' that mentally disordered firesetters followed through the model was conducted; each participant was plotted through the model and any common patterns were identified ${ }^{2}$. Participants appeared to follow one of three pathways through the model: 'fire interest-childhood mental healthapproach' ( $n=11)$, 'no fire interest-adult mental health' $(n=7)$, and 'fire interest-adult mental health' $(n=4)$. Participants who followed the 'fire interest-childhood mental healthapproach' pathway developed at least two fire risk factors and mental health problems in childhood. Participants who followed this pathway were therefore more likely to engage in detailed planning of the fire, experience positive fire related affect, and watch the fire. Participants who followed the 'no fire interest-adult mental health' pathway generally did not develop any fire risk factors in childhood and their mental health issues tended to onset proximally to the fire; the offense was generally unplanned, however, if there was any planning it was low level and very proximal to the offense, and these participants also tended to feel indifferent about setting the fire, and did not watch it. Participants who followed the 'fire interest-adult mental health' pathway developed at least two fire risk factors in childhood, did not experience mental health problems until adulthood, engaged in low level planning of the fire, and generally watched the fire unless contextual circumstances did not

\footnotetext{
${ }^{2}$ One individual could not be classified as their hospital files provided insufficient information to track them through the pre-offence and offence phases of the model.
} 
allow (i.e., wanted to avoid detection or were trying to protect themselves). No pathways were found that appeared to reflect the sex of the participant.

\section{Discussion}

The current research developed the first offense chain model of firesetting in mentally disordered offenders. There are several prominent aspects to the Firesetting Offense Chain Model for Mentally Disordered Offenders (FOC-MD) one particularly significant aspect of the model is that it emphasises the importance of early experiences of fire in childhood and how this contributes to firesetting in adulthood. Further, the FOC-MD highlights how the affective responses mentally disordered firesetters develop towards fire, as a result of childhood experiences can be either strongly positive or negative. The development of either strong positive or strong negative affect towards fire appears to be predictive of adult firesetting for a subgroup of offenders. Existing research in the field has reported the existence of childhood fire interest and juvenile firesetting (Rice \& Harris, 2008) as risk factors for repeat firesetting (Rice \& Harris, 1991). The current offense chain model also suggests that these are important risk factor for adult firesetting in mentally disordered offenders. Further, early fire experiences and exposure to fire have also been documented in the existing literature as having some impact on future firesetting in non-mentally disordered adolescent firesetters; these experiences have been reported as being either positive (i.e., father having significant employment involving fire, Macht \& Mack, 1968) or negative (i.e., high incidence of burns sustained as a result of abuse; Ritvo, Shanok, \& Lewis, 1983). However, to our knowledge firesetter's affective responses to early experiences with fire have never been highlighted in the existing firesetting literature.

Our empirical study suggests that some mentally disordered firesetter's early experiences with fire, and in particular the strong fire-related affect they develop as a result of these experiences towards fire, play an integral role in their offense process. These feed into 
the development of fire related risk factors in childhood which in turn impact other aspects of the individual's firesetting behavior (i.e., planning, fire ignition, and whether they watch the fire). For example, individuals who experience fire negatively in childhood may go on to use fire as a tool to inflict harm or induce fear in others (e.g., for revenge as they perceive it as a powerful tool in which to do this).

A second key feature of the FOC-MD is the contributory role that mental health plays in an incident of firesetting for mentally disordered firesetters. Mental health problems have consistently been reported in the literature as being a risk factor for mentally disordered firesetters (Barnett et al., 1997; Dickens et al., 2009; Lindberg, Holi, Tani, \& Virkkunen, 2005). However, the current study suggests that mental health problems are not necessarily a risk factor per se; instead they develop after or alongside other vulnerabilities/risk factors and in turn make these more acute. This finding appears to be consistent with new theoretical developments in the field which suggests that mental health may act largely as a moderator for firesetting, increasing the likelihood of repeat firesetting subject to the presence of other predictive risk factors (M-TTAF; Gannon et al., 2012). In addition to this, the FOC-MD highlights that the onset of mental illness for mentally disordered firesetters can span from childhood to within a short period before setting the fire, emphasising that not all mentally disordered firesetters have long-term psychiatric histories.

The final salient aspect of the FOC-MD is that it accounts for a wide range of motives for firesetting and acknowledges the non-mutual exclusivity of these. Unlike previous research in the area, the FOC-MD allows for the identification of multiple motives for each individual firesetter thus providing a more complete and holistic account of the contributory motivational factors that precede an incident of firesetting. Commonly identified motives were apparent in the current model (i.e., revenge, cry for help/suicide, fire interest, and boredom) consistent with existing research in the area (Geller, 1992; Ritchie \& Huff, 1999; 
Rix, 1994). However, the model also highlights a new motive that has not been previously discussed in the literature, protection. This is interesting as it suggests that a proportion of mentally disordered firesetters set fires as a defensive tool to protect themselves from perceived harm as opposed to an aggressive or acquisitive tool. In addition to the identification of a new motive, the model also allows for the greater emphasis on the role of hallucinations in the offense process. Hallucinations have been considered historically as a motive in their own right for firesetting (Virkkunen, 1974), however, consistent with recent theoretical developments (M-TTAF, Gannon et al., 2012) the current research suggests that hallucinations intensify any pre-existing motives for firesetting for the majority of those who experience them as opposed to being a sole motivator themselves.

Clinically, the FOC-MD has several key treatment implications for practitioners working with mentally disordered firesetters. Firstly, the offense chain model of firesetting in mentally disordered offenders highlights the necessity for clinicians to explore mentally disordered firesetters' childhood experiences of fire and the cognitive and affective reactions that they had to these. It also emphasises the need to work with mentally disordered firesetters in treatment on how to manage existing risk factors in the context of mental illness. This is consistent with existing good clinical practice as practitioners working with such individuals should be exploring the effects of childhood experiences of fire as well as the role of mental illness when making case formulations. Finally, a simplified version of this model could be utilised by professionals working with mentally disordered firesetters in treatment to help explain individual's own offense processes so that offenders can understand their individual risk factors for relapse. For example, helping mentally disordered firesetters understand the thoughts, feelings and events that led to them setting a fire and how childhood experiences with fire may relate to their adult firesetting. Further, the different pathways that 
have been identified through the model provide guidance for the development of specific treatment programs for different subtypes of firesetters.

The FOC-MD has a number of strengths, the model gives a detailed account of the cognitive, affective, behavioral, and contextual factors that appear to be related to and contribute to an act of deliberate firesetting for both male and female mentally disordered offenders. In addition to this, the intricate and flexible nature of the model means that features common to different types of mentally disordered firesetters can be determined whilst still being able to accommodate individual differences in offense styles.

Although there are there are several key strengths to the FOC-MD, there are some identifiable limitations that necessitate discussion. One limitation of the current research is the small sample size. The FOC-MD was developed with qualitative accounts from 23 mentally disordered firesetters; given that approximately $10 \%$ of patients in forensic mental health services have firesetting in their offense history (Coid et al., 2001) our sample accounts for just $5.2 \%$ of the current total population of mentally disordered firesetters in secure forensic psychiatric settings. In addition to this, the numbers of female firesetters that are represented in the model are fairly low, especially since research suggests that female firesetters are overrepresented in high security inpatient settings (Dickens \& Sugarman, 2012). As a result of this, certain offender types were inevitably under-represented (i.e., those who had engaged in self-immolation and attempted suicide by fire, and those who had set fire for personal gain or to conceal a crime). Nonetheless as noted by previous researchers (Gannon et al., 2008; Polaschek, Hudson, Ward, \& Siegert et al., 2002) a primary strength of models developed using grounded theory is the ability for future adaptation and modification in reaction to additional data. Therefore the FOC-MD has the capacity to develop and accommodate the offender types that are currently under-represented. 
There are also several limitations associated with the utilisation of grounded theory that may have impacted upon the validity and reliability of the model. Most important is that the methodology relies on the accuracy of self-reports of offense accounts from offenders. These self-reports may have been affected by a tendency of participants to present themselves in a socially desirable manner (i.e., underreporting fire interest, and cognitions and emotions experienced as part of setting the fire) as well as distorted memories of the offense and how it unfolded due to a loss of details in recollection over the time period since the offense. To try and minimize the effects of such issues on the validity of the research participants' hospital and prison files were examined post interview to look for any inconsistencies in the offense accounts provided by participants. Any information provided in the interviews that significantly differed from file information was therefore removed from analysis to strengthen and maintain the model validity.

A second methodological limitation of the current research regards whether the preliminary model represents some implicit researcher bias, for example reflecting our knowledge and theory from the existing firesetting literature. To minimize any potential effects of implicit researcher bias some of the data was collected by the fourth and sixth authors who were largely unaware of the firesetting literature and the model was developed by the first two authors together to reduce any individual biases. However, similarly to other offense chain models, cross-validation of the current model should still be conducted to strengthen and validate its underlying conceptual principles, and specific pathways that mentally disordered firesetters follow within the model should be identified and examined.

In conclusion, the FOC-MD represents, to our knowledge, the very first attempt to document mentally disordered firesetters offense process behavior. Employing grounded theory methodology has allowed us to develop a preliminary model with considerable theoretical scope in an area that lacks both theoretical and empirical research. The FOC-MD 
is sensitive enough to distinguish between different subtypes of mentally disordered firesetters whilst also acknowledging the homogeneity of some characteristics across mentally disordered firesetters as a population. In addition to this, the current model highlights further valuable areas of research which we encourage other researchers and practitioners to build upon.

\section{Acknowledgements}

We would like to dedicate this article to Trevor Naylor (1946-2013) whose candid and thoughtful descriptions of fire and its misuse inspired us to investigate the area of firesetting and to design this study.

We would also like to specially thank Professor Tony Ward for his guidance and comments on the analysis process conducted as part of this project, staff at the participating hospitals and prisons, and our participants for sharing their experiences with us.

This research was partially supported by an Economic and Social Research Council grant awarded to Theresa A. Gannon (RES-062-23-2522). 


\section{References}

Barnett, W., Richter, P., Sigmund, D., \& Spitzer, M. (1997). Recidivism and concomitant criminality in pathological firesetters. Journal of Forensic Science , 42, 5, 879-883.

Barnett, W., \& Spitzer, M. (1994). Pathological fire-setting 1951 - 1991: A review. Medicine, Science and the Law. , 34, 4 - 20.

Cassar, E., Ward, T., \& Thakker, J. (2003). A descriptive model of the homicide process. Behavior Change, 20, 2, 76 - 93. doi: 10.1375/bech.20.2.76.24840

Chambers, J.C, Ward, T., Eccleston, L., \& Brown, M. (2009). The pathways model of assault: A qualitative analysis of the assault offender and offense. Journal of Interpersonal Violence, 24, 1423-1449. doi: 10.1177/0886260508323668

Coid J., Kahtan, N., Gault, S., Cook, A., \& Jarman, B. (2001). Medium secure forensic psychiatry services: Comparison of seven English health regions. British Journal of Psychiatry, 178, 55 - 61. doi: 10.1192/bjp.178.1.55

Criminal Damage Act (1971). United Kingdom.

Dickens, G., Sugarman, P., Edgar, S., Hofberg, K., Tewari, S., \& Ahmad, F. (2009). Recidivim and dangerousness in arsonists. Journal of Forensic Psychiatry \& Psychology , 20, 5, 621-639. doi: 10.1080/14789940903174006

Dickens, G., \& Sugarman, P. (2012). Adult firesetters: Prevalence characteristics and psychopathology. In Dickens, G.L., Sugarman, P.A., Gannon, T.A. (eds) Firesetting and Mental Health (pp. 3-27). London: RCPsych. 
Fazel, S., \& Grann, M. (2002). Older criminals a descriptive study of psychiatrically examined offenders in Sweden. International Journal of Geriatric Psychiatry, 17, 907913. doi: $10.1002 / \mathrm{gps} .715$

Fineman, K.R. (1980). Firesetting in childhood and adolescence. Child psychiatry: Contributions to diagnosis, treatment and research. Psychiatric Clinics of North America, 3, 3, 483 - 500.

Fineman, K.R. (1995). A model for the qualitative analysis of child and fire deviant behavior. American Journal of Forensic Psychology, 13, 1, 31 - 60.

Freud, S. (1932). The acquisition of power over fire. International Journal of Psychoanalysis, $13,405-410$.

Gannon, T.A., \& Barrowcliffe, E. (2012). Firesetting in the general population: The development and validation of the firesetting and fire proclivity scales. Legal and Criminological Psychology, 17(1), 105-122. doi: 10.1348/135532510X523203

Gannon, T.A., Lockerbie, L., \& Tyler, N. (2012). A long time coming? The Firesetting Intervention Program for Mentally Disordered Offenders. Forensic Update, 106, 110.

Gannon, T.A., Ó Ciardha, C., Doley, R., \& Alleyne, E.K.A. (2012). The Multi-Trajectory theory of Adult Firesetting (M-TTAF). Aggression and Violent Behavior, 17(2), $107-$ 121. doi: 10.1016/j.avb.2011.08.001

Gannon, T. A. \& Pina, A. (2010). Firesetting: Psychopathology, theory and treatment. Aggression and Violent Behavior, 15, 224-238. doi: 10.1016/j.avb.2010.01.001 
Gannon, T.A., Rose, M.R., \& Ward, T. (2008). A descriptive model of the offense process for female sexual offenders. Sexual Abuse: A Journal of Research and Treatment, 20, 3, 352-374. doi: 10.1177/1079063208322495

Geller, J.L. (1992). Arson in review: From profit to pathology. Hospital and Community Psychiatry, 15, 623-645.

Gordon-Finlayson, A. (2010). Grounded Theory. In M.A. Forrester (ed) Doing Qualitative Research in Psychology: A Practical Guide. SAGE Publications: London (pp. 154176).

Hollin, C.R. (2012). Arson: treatment and interventions. In G.L. Dickens, P.A. Sugarman, T.A. Gannon. (Eds) Firesetting and Mental Health (pp. 224- 239). London: RCPsych.

Home Office (2012). Recorded Crime Statistics 2002/3 - 2009/10. Retrieved from http://www.homeoffice.gov.uk/publications/science-research-statistics/researchstatistics/crime-research/crime-stats-2002-

Jackson, H.F. (1994). Assessment of fire-setters. In M. McMurran, \& J. Hodge (Eds.), The assessment of criminal behaviors in secure settings (pp. 94-126). London: Jessica Kingsley.

Jackson, H.F., Hope, S., \& Glass, C. (1987). A functional analysis of recidivistic arson. British Journal of Clinical Psychology, 26, 175-185. doi: 10.1111/j.20448260.1987.tb01345.x

Kalmar, D.A., \& Sternberg, R.J. (1988). Theory knitting: An integrative approach to theory development. Philosophical Psychology, 1, 153-170. doi:

$10.1080 / 09515088808572934$ 
Lindberg, N., Holi, M.M., Tani, P., \& Virkkunen, M. (2005). Looking for pyromania: Characteristics of a consecutive sample of Finnish male criminals with histories of recidivist fire-setting between 1973 and 1993. BMC Psychiatry, 5, 47, 1-5. doi: $10.1186 / 1471-244 X-5-47$

Macht, L.B., \& Mack, J.E. (1968). The firesetter syndrome. Psychiatry, 31, 277 - 288.

Ministry of Justice. (2011). Number of persons proceeded against at the magistrates' courts and found guilty and sentenced at all courts for Arson, by gender and age group, England \& Wales in 2009. London.

Murdoch, S., Vess, J., \& Ward, T. (2010). Descriptive model of female violent offenders: distal background variables. Psychiatry, Psychology and Law, 17, 3, 368-384. doi; $10.1080 / 13218710903421316$

Palmer, E.J., Caulfield, L.S., \& Hollin, C.R. (2007). Interventions with arsonists and young fire setters: A survey of the national picture in England and Wales. Legal and Criminological Psychology , 12, 101 - 116. doi: 10.1348/135532505X85927

Palmer, E. P., Hollin, C. R., Hatcher, R. M., \& Ayres, T. (2010). Arson. In F. Brookman, T. Bennett, M. Maguire, and H. Pierpoint. Handbook on crime. Cullompton, Devon: Willan.

Polaschek, D.L.L., Hudson, S., M., Ward, T., \& Siegert, R.J. (2002). Rapists’ offense processes: A preliminary descriptive model. Journal of Interpersonal Violence, 16 (6), 523-544. 
Repo, E., Virkkunen, M. , Rawlings, R., \& Linnoila, M. (1997). Criminal and psychiatric histories of Finnish arsonists. Acta Psychiatrica Scandinavia, 95, 318 - 323. doi: 10.1111/j.1600-0447.1997.tb09638.x

Rice, M.E., \& Harris, G.T. (1991). Firesetters admitted to a maximum security psychiatric institution. Journal of Interpersonal Violence , 6, 461-475. doi: $10.1177 / 088626091006004005$

Rice, M.E., \& Harris, G.T. (2008). Arson. In V. Parrillo, (Ed.) The encyclopedia of social problems. Thousand Oaks, CA: Sage.

Ritchie, E.C., \& Huff, T.G. (1999). Psychiatric aspects of arsonists. Journal of Forensic Science, 44, 4, 733-740.

Ritvo, E.,K., Shanok, S.S., \& Lewis, D.O. (1983). Firesetting and non-firesetting delinquents: A comparison of neuropsychiatric, psychoeducational, experimental and behavioral characteristics. Child Psychiatry and Human Development, 13, 259 - 267.

Rix, K.J.B. (1994). A psychiatric study of adult arsonists. Medicine, Science and the Law, $34,21-24$.

Strauss, A., \& Corbin, J. (1998). Basics of qualitative research: Techniques and procedures for developing grounded theory (2nd ed.). Thousand Oaks, CA: Sage.

Swaffer, T., Haggett, M., \& Oxley, T. (2001). Mentally disordered firesetters: a structured intervention program. Clinical Psychology and Psychotherapy, 8, 468-475. doi: 10.1002/cpp.299 . 
Taylor, J.L., Thorne, I., Robertson, A. and Avery, G. (2002). Evaluation of a group intervention for convicted arsonists with mild and borderline intellectual disabilities, Criminal Behavior and Mental Health, 12, 282-293.

Tyler, N., \& Gannon, T.A. (2012). Explanations of firesetting in mentally disordered offenders: A review of the literature. Psychiatry: Interpersonal and Biological Processes, 75, 2, 149 - 165. doi: 10.1521/psyc.2012.75.2.150

Virkkunen, M. (1974). On arson committed by schizophrenics. Acta Psychiatrica Scandinavia, 50, 2, 152 - 160. doi:10.1111/j.1600-0447.1974.tb08204.x

Vreeland, R., \& Levin, B. (1980) Psychological aspects of firesetting. In D. Canter (ed.), Fires and Human Behavior (pp. 31-46). Chichester, England: Wiley.

Ward, T., \& Hudson, S.M. (1998). A model of the relapse process in sexual offenders. Journal of Interpersonal Violence, 13, 129-155. doi: 10.1177/088626098013006003

Ward, T., Louden. K., Hudson, S.M., \& Marshall, W.L. (1995). A descriptive model of the offense chain for child molesters. Journal of Interpersonal Violence, 10, 452-472. doi: $10.1177 / 088626095010004005$

Ward, T., Polaschek, D. L. L., \& Beech, A. R. (2006). Theories of sexual offending. Chichester, UK: Wiley

Willig, C. (2008). Introducing Qualitative Research in Psychology, $2^{\text {nd }}$ edition. Open University Press: Berkshire, England (pp. 34-50). 
Figure 1: Background Factors

\section{Phase 1; Background Factors}

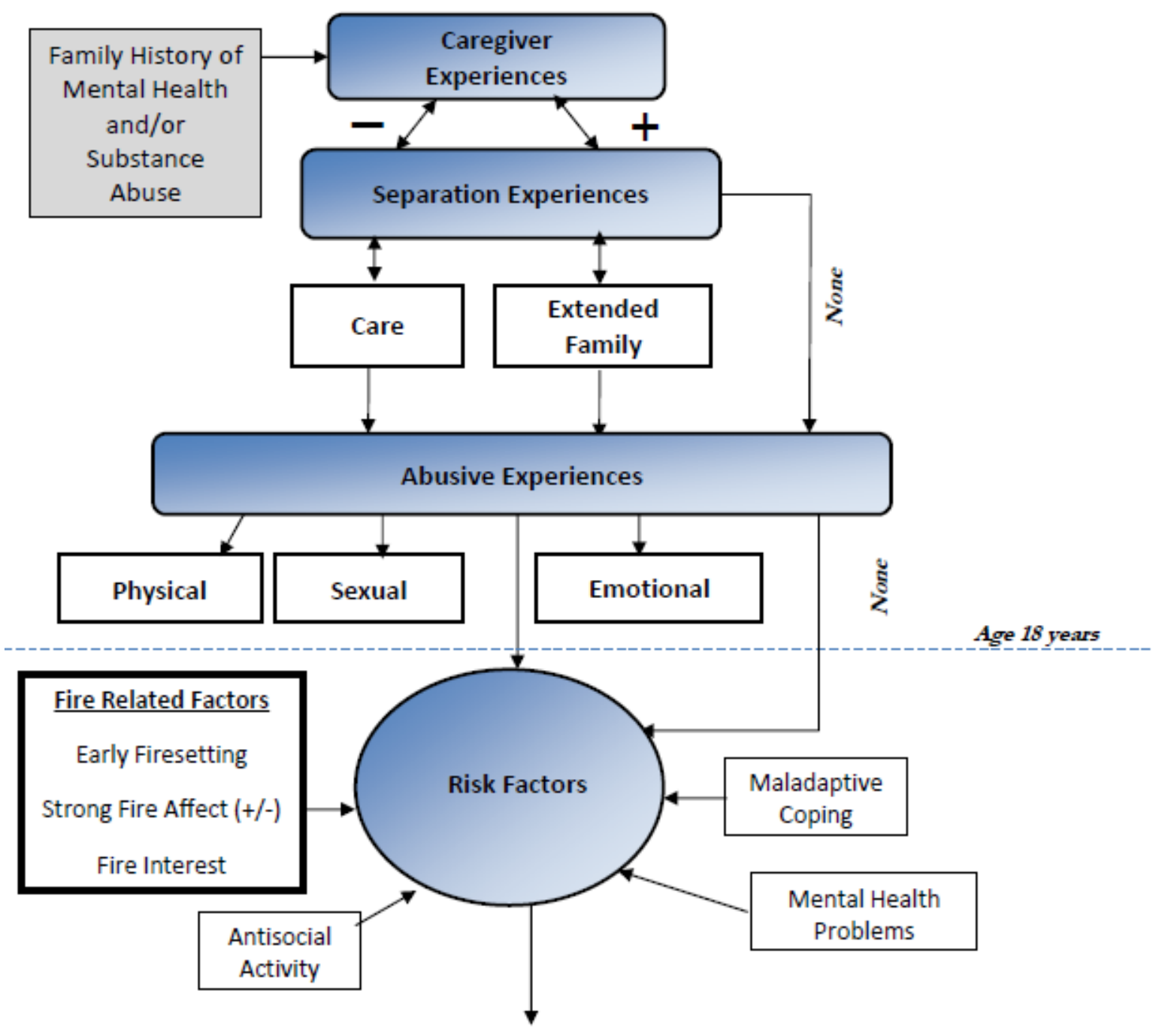


Figure 2: Early Adulthood and Pre-Offense Period

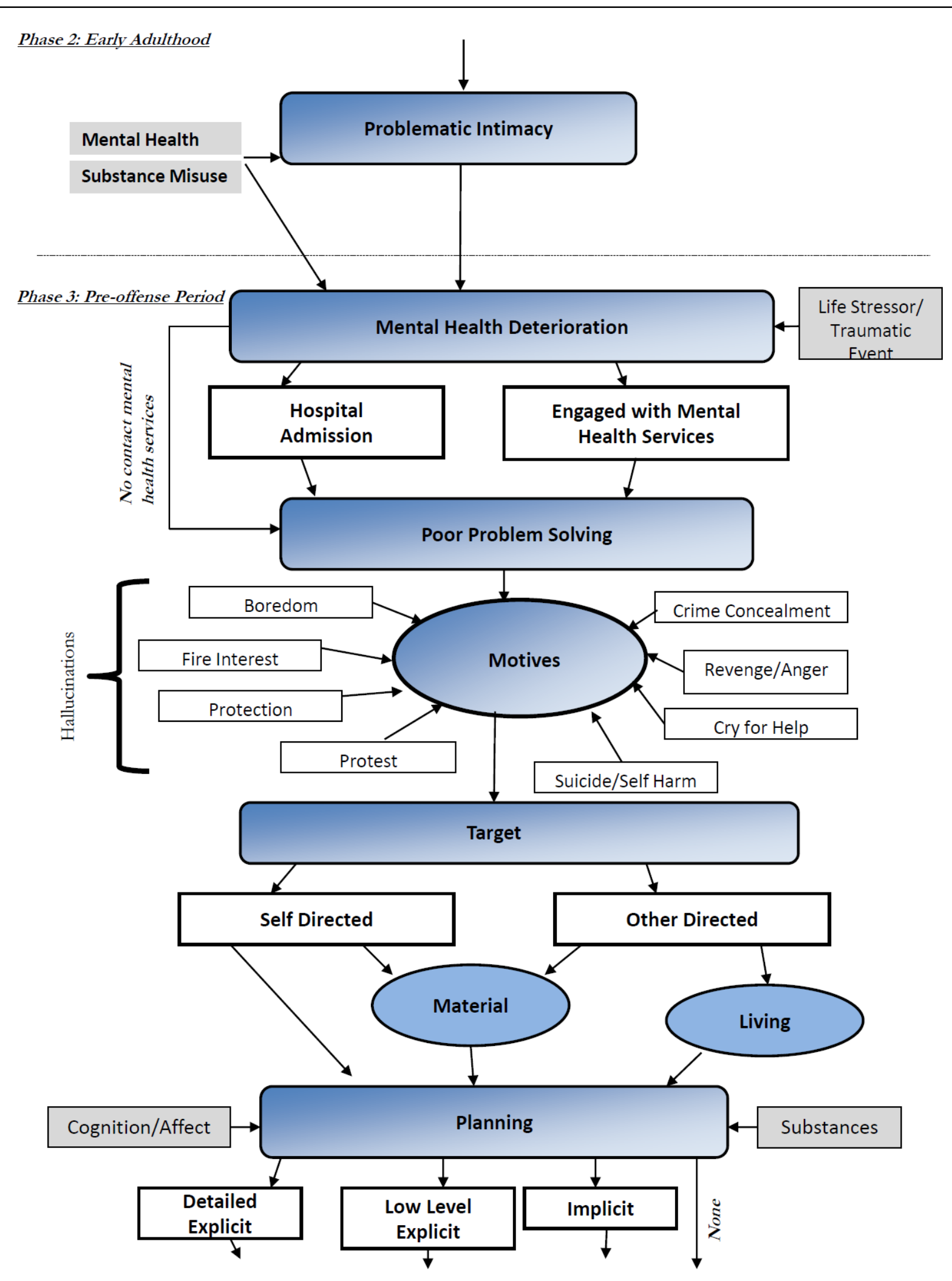


Figure 3: Offense and Post Offense Period

Phase 4: Offense and Post OffensePeriod

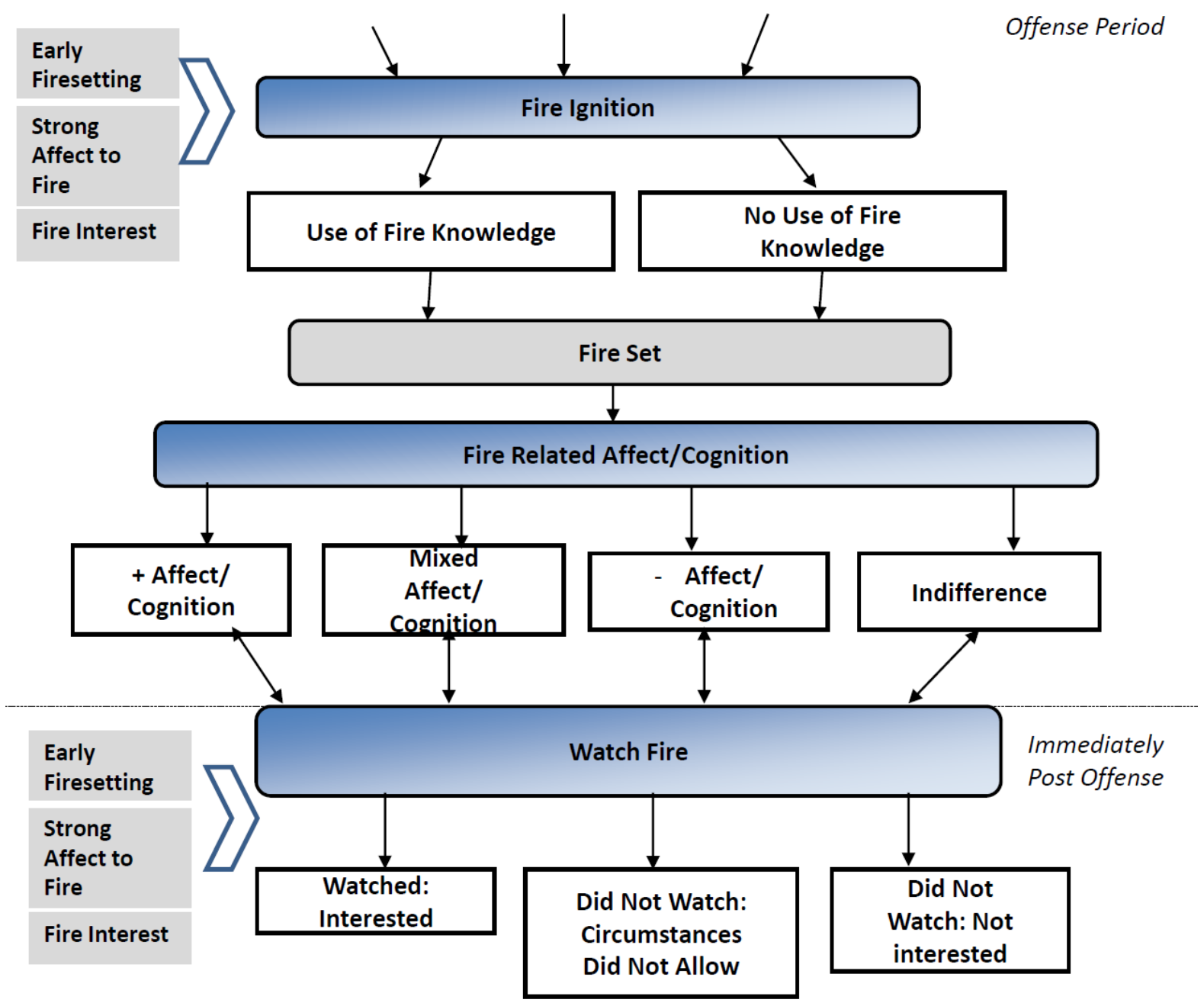

